\title{
First-Generation African American Male College Students: Implications for Career Counselors
}

\author{
Delila Owens \\ Krim Lacey \\ Glinda Rawls \\ JoAnne Holbert-Quince
}

\begin{abstract}
The path to upward mobility or economic success for African American men is often filled with obstacles and roadblocks. Many first-generation African American men entering colleges and universities face limited resources and opportunities to aid in their career development and efforts to meet their career objectives. This article explores the career development needs of African American men attending colleges and universities. The article provides suggestions, techniques, and strategies that career counselors and student affairs personnel can use to assist these African American men in their career development. Implications for career counselors are also addressed.
\end{abstract}

Supporting the career development of African American men continues to be an important area of exploration. According to the latest statistics retrieved from the U.S. Department of Education, National Center for Education Statistics (Snyder \& Hoffman, 2003), approximately $55.7 \%$ of African Americans graduated from high school and enrolled at a 4-year institution. Although this figure provides an indication of the growing number of African American students seeking a college or university education, it belies the fact that there is still a large disparity in rates of enrollment between White and African American college students (Bennett \& Xie, 2000). Although the immediate college enrollment gap has narrowed over the years, White students continue to enroll in college at a higher rate than do African American students (Snyder \& Hoffman, 2003). This gives White students a significant advantage over African American students in terms of social economic status and access because of education.

There are nearly limitless benefits and gains that come with a college degree. To begin with, a college education allows both social and economic access that is typically not afforded to individuals who are noncollege graduates. In fact, in the year 2005 alone, African

Delila Owens and JoAnne Holbert-Quince, Department of Theoretical and Behavioral Foundations, Wayne State University; Krim Lacey, Institute for Social Research, University of Michigan; Glinda Rawls, University Counseling and Testing Center, Western Michigan University. Correspondence concerning this article should be addressed to Delila Owens, Department of Theoretical and Behavioral Foundations, College of Education, Wayne State University, 5425 Gullen Mall, 317 COE, Detroit, MI 48202 (e-mail: owens@wayne.edu). 
Americans who held a bachelor's degree had earned incomes that were substantially higher than those of African Americans who had only some college experience or who did not have any college education (U.S. Department of Education, National Center for Education Statistics, 2007).

Nonetheless, although the earning potential for African Americans with degrees may appear promising, the promise of such success is severely hampered by low college completion rates. The college completion rate of African Americans continues to lag behind that of other racial and ethnic groups. A disproportionate number of African American men attend colleges with graduation rates lower than those of the colleges attended by their White and Asian counterparts (Stoops, 2004). Although there has been a $4 \%$ improvement in the graduation rates among African American college students in general, this increase is not very substantial (Stoops, 2004). Furthermore, the average length of time African American men take to complete their college degree is longer than that of their White counterparts (Trusty, 2004). These statistics not only have countless implications for the socioeconomic status of African American men, but also have ramifications for first-generation students entering colleges or universities.

As has been discussed and as is evidenced by statistics, having a higher level of education provides better opportunities for greater income and the potential of career advancement. Given that a relatively large percentage of African Americans entering college are first-generation students and considering the low completion rate among this group, it is of importance to explore means to improve their college completion rates.

In this article, we therefore discuss ways that college counselors and student affairs professionals can support African American students in their career development. We focus primarily on first-generation African American male college students and discuss ways in which career counselors and student affairs professionals can provide support to address the low college retention rate among this group. This low retention is also striking when considered across gender lines, with African American men having disproportionately lower college completion rates than those of African American women (Wilson, 2000).

\section{Experiences of First-Generation African American Male College Students and Career Development}

Some researchers have indicated that approximately $27 \%$ of all high school graduates in the United States are considered first-generation college students (i.e., neither parent attended college; Choy, 2001; Hertel, 2002). Among those within this population with intentions of pursuing a postsecondary education, African American students have been found to be less academically prepared for the rigor of college courses and have limited information about the college process in general (Thayer, 2000). This is partly due to the fact that many 
of these students live in poverty. Poverty affects not only learning opportunities but also the potential to succeed in school (Hughes, Stenhjem, \& Newkirk, 2007). More often than not, poor and minority students are placed in less challenging classes and attend schools with low graduation rates and that vary in academic rigor and quality of instruction (Hughes et al., 2007). As researchers have highlighted, some of these factors are important predictors in the success of college students (Adelman, 1999; Trusty, 2004).

Along with the instructional barriers that some of these students experience during their early academic years, many who continue on to college also encounter a conflict between the college environment and the cultures in which they were raised (Thayer, 2000). In particular, their home communities are perceived as welcoming because of the familiarity with the environment, whereas the college environment is not. Individuals within these home environments often share similar ethnic characteristics and interests. Furthermore, the home environments where many ethnic minority first-generation college students are raised both provide and reinforce their cultural identity, which is not typically the case on many college campuses. There is a tendency for ethnic minority students, such as African Americans, to experience resistance, alienation, and a culture that is dissimilar to the one to which they are accustomed (Hurd, 2000). As a result, they lack a sense of belonging. This lack of belonging presents a challenge to achievement of their scholastic goals and to their graduation.

Feelings of being connected to college environments are associated with persistence, particularly for the lst-year student (Hoffman, Richmond, Morrow, \& Salomone, 2002). Persistence in college is especially influenced by the successful transition of the student to this new environment and by her or his perception of the campus racial climate (Locks, Bowman, Hurtado, \& Oseguera, 2006). Because belonging, persistence, transition, and perceived racial climate are significant to student adjustment in college settings, it is important for student affairs professionals to explore these factors as a way to help first-generation African Americans successfully integrate into the college environment.

This connection to their college environment is especially needed for African American male college students, whose educational experiences can often mirror the experiences they face in society. In particular, the influences of environmental and cultural factors such as racism, disenfranchisement, and low achievement tend to impede the academic progress of these students (Garibaldi, 1992). For instance, in the year 2000, statistics showed that $65 \%$ of African American men who were high school dropouts were unemployed in their 20s (Booth, 2006).

These findings suggest that an understanding of the experiences of African American men in society may contribute to an improvement in their career preparation and development during their college years. Furthermore, student affairs personnel must recognize that African American men are a unique group in that they are disadvantaged by inadequate educational preparation, low high school graduation and college attendance rates, as well as high unemployment and incarceration rates. Given this reality, there may in fact be a need for special 
support that institutions must be systematically equipped to provide. Superficially addressing the needs of African American men is not enough (Noguera, 2005).

Student affairs professionals are also encouraged to focus on firstgeneration African American male college students because they represent a disproportionately small percentage of the total college population (Cuyjet, 1997). Because of the small number of students within this population, it may be worthwhile to provide special support and a nurturing surrounding to assist this group to appropriately adapt to their environment and successfully move toward graduation.

It is apparent that first-generation African American male college students have special needs because of the instructional barriers they may have experienced prior to their admittance to postsecondary institutions (Cuyjet, 1997; De León, 1996). Cuyjet (1997) suggested that the inadequate preparation of these students stems from attendance at elementary and secondary schools that were low performing, adults' and peers' lower expectations of their academic abilities, peer influence that encourages a disinterest in academic achievement, and financial barriers that limit their access to proper resources. Because of these limitations, it is important for career counselors and student affairs professionals to create an environment that is embracing, nurturing, and less hostile for African American men. Essentially, what is required is an academic environment that is welcoming and supportive for African American men (Fleming, 1984).

First-generation African American male students who are entering colleges and universities across the country may also need extensive support in the development and implementation of their career plans because of their lack of information about and exposure to college environments-a lack that significantly contributes to the vulnerability of these students (Hertel, 2002). Student affairs professionals are urged to provide first-generation African American male college students with career education and counseling that will enable them to choose a personally satisfying career that fits both their abilities and their interests. To do so, counselors must develop a firm knowledge and understanding of the worldviews of African American men (Walsh, Bingham, Brown, \& Ward, 2001). As they attempt to assist and implement career development plans, counselors must be keenly aware of the challenges African American men have faced over time.

Finally, given the relatively low college completion and high dropout rates for this group, retention efforts should be a focal point for firstgeneration African American male college students. Regarding this effort, Tinto (2003) noted that universities must be serious about retention and actively initiate changes in their own structures and practices to better meet the needs of diverse student bodies. As Townsend (1994) suggested, financial aid, strong mentoring, achieving a critical mass of diverse students, faculty involvement, and instructional commitment may also be key factors to retaining African American students.

\section{Theories of Career Development}

Career counselors' theoretical base often forms the foundation for defining and establishing their working alliance with African American 
male college students. There is a vast array of career development theories developed by the likes of Super, Roe, and Holland. These theories often serve as a guide to the implementation of career plans, but unfortunately many of the older theories have been justly criticized for overlooking issues pertinent to clients of color (Lee \& Armstrong, 1995). For example, there is an assumption that the career development process is sequential; however, in most cases this does not hold true across ethnic groups, including African American clients (Cook, Heppner, \& O’Brien, 2002).

As newer theoretical perspectives (i.e., social cognitive career theory and constructivist theory) have been developed to address diverse issues surrounding culture, gender, and social context that influence career choices, there are lingering questions as to whether these theories are specific enough to groups who have encountered obstacles and challenges that are unique when compared with others. Because African American clients face external challenges that are distinct from those of their White counterparts, there is still a growing need for the expansion of culturally sensitive career counseling theories (Chung, 2003; Whiston, 2003). These theories should address the day-to-day realities that clients of color face.

In addition to the need for culturally sensitive theories, special counseling skills and a deeper understanding and knowledge of ethnic minorities may be warranted. Counseling African American clients will require career counselors to be knowledgeable about the cultural values and differences within various African American groups (Kimbrough \& Salomone, 1993). Career counselors must also recognize the environmental barriers facing African American men in pursuit of their career goals (Lent \& Brown, 1996). Although having a strong knowledge base may be the initial step to understanding and counseling African American men, it is not enough. Career counselors must show a willingness to assist and effectively work with African American clients in coping with some of these barriers.

\section{Implications for Career Counselors}

The literature described in this article has several implications for college counselors and student affairs professionals who seek to support first-generation African American male college students in their career development process. There are several things that counselors can do in this regard, including listening to the perspectives of these students, being willing to discuss racism and discrimination, explaining the importance of networking with faculty and alumni, encouraging students to join professional and student organizations, and assisting students to manage and negotiate relationships with other individuals throughout the institution and in society. The following are additional strategies and techniques that can be used to assist African American men.

1. Career counselors must be comfortable enough with clients to establish a working alliance that will enable the counselor to effectively listen to and meet the career development needs of the client (Parham \& Austin, 1994). 
2. Counselors can establish partnerships between high schools and colleges as a step in assessing the challenges and advancement needs of African American men.

3. Counselors should recruit appropriate role models to speak about careers in which African Americans have traditionally been underrepresented and what it takes to enter those particular fields (Murry \& Mosidi, 1993).

4. Counselors should address with their clients the role of racism and discrimination and the educational and socioeconomic barriers that may hamper career advancement (Hughes et al., 2007). Counselors may help to provide African American men with the resources and effective strategies to overcome these challenges or effectively cope with them.

5. Counselors should be active in alleviating pessimism and fears that African American men have about their chances to succeed in society. This could be accomplished by reinforcing the successes of other African American men who have risen to prominence despite the challenges they faced throughout the course of their lives.

6. Counselors should work to implement one-to-one mentoring and tutoring programs to address academic needs (Hughes et al., 2007).

7. Counselors should work to address the financial issues that prevent many students of color from completing school and meeting career objectives. Financial problems have been identified in the research literature as one reason for the low completion rate among minority students (Ishitani \& DesJardins, 2002).

8. Counselors should attempt to connect African American men with the wider community through service learning (Hughes et al., 2007).

9. Counselors must pay attention to the students' long-term educational and career goals and the degree of consistency between these goals and academic efforts (Trusty, 2004).

10. Counselors should inform students of various postsecondary educational and career options and help students with backup plans (Trusty, 2004).

11. College counselors can assist African American men on college campuses by allowing them to voice their experiences and by listening to their perspectives. College counselors must not become unsympathetic toward African American men and cannot allow negative stereotypes to impede their ability to counsel this population. They must recognize that all individuals are uniquely gifted in their own right. Counselors must listen to the experiences of African American men and assist by validating their experiences on campus.

12. Effective college counselors and career professionals have an obligation to inform students of the issues that they may face upon entering the workplace, particularly the reality that some people may hold perceptions of, attitudes about, and biases toward African American men. College counselors must help students understand and deal with the issues of racism and discrimination.

13. College counselors must connect students with the proper resources across campus. They must explain the importance of networking and career development as keys to students' career success. It is important to connect students to resources because some students 
may not be aware of or seek out the information on their own. As an initial step, counselors may seek out professional organizations that will assist students with career plans and provide mentoring.

14. College counselors should encourage African American men to seek out mentors. Researchers have documented the importance of African American students having mentors in their field of study (Falconer \& Hays, 2006; Wasonga, Christman, \& Kilmer, 2003). Perhaps an alumni database that connects African American students with African American alumni in their field of study would be beneficial. Gloria, Kurpius, Hamilton, and Willson (1999) found that mentors can also be important in helping students progress through and complete college.

15. College counselors should implement outreach programs. In general, African Americans can be reluctant to seek counseling and health services (Falconer \& Hays, 2006). Hence, it is important that career counselors provide outreach programming around the campus to reach students who would not ordinary come to the counseling center. This can be accomplished by offering career workshops in the residence halls across campus, hosting careerrelated panels throughout the academic year, and/or creating electronic newsletters from the career development office.

16. College counselors should build relationships with African American student organizations. This is crucial because these connections will help career centers reach African American students and could enhance the credibility of programming efforts geared toward addressing the career development needs of African Americans (Falconer \& Hays, 2006).

17. Counselors and student affairs professionals should be active in the development of policies and practices that seek to integrate more African American male counselors into predominantly White institutions. These counselors may provide indirect role modeling for African American men and encourage them to seek counseling. As has been noted, African American men have been found to be less likely than other groups to seek counseling (Walsh et al., 2001).

\section{Conclusion}

Supporting the career development needs of first-generation African American male college students is crucial. An important aspect of career counseling with African American clients involves exploring interests, goals, and abilities in relation to their worldview. Career counselors and other student affairs professionals who assist African American men must understand the complex intersection of race and class in the lives of these men. However, because of the influence that race has on the lives of people of color, it is important that career professionals are open to learning the frame of reference of African American men. This knowledge gives counselors an understanding of their clients' experiences with the world. They must also be receptive to developing the necessary skills to effectively and competently assist African American men. Hence, competently addressing the career development needs of first-generation 
African American male college students will require learning, support, and a sincere desire to understand their unique life experiences. It may also be wise to have more counselors of color on college campuses who are equipped to capably administer culturally sensitive counseling strategies (Sue \& Sue, 2003). Even after implementing all of these approaches, it is still left up to the career counselors to be willing to advocate for their clients and actively integrate their clients' community and life experiences into the career development process.

\section{References}

Adelman, C. (1999). Answers in the tool box: Academic intensity, attendance patterns, and bachelor's degree attainment [Monograph]. Retrieved from U.S. Department of Education website: http://www.ed.gov/pubs/Toolbox/index.html

Bennett, P. R., \& Xie, Y. (2000). Explaining the Black-White gap in college attendance: Racial differences versus socioeconomic determinants (Population Studies Center, University of Michigan, Report No. 00-447). Retrieved from ERIC database. (ED443905)

Booth, D. (2006). Why are so many Black men in prison? Bloomington, IN: Xlibris.

Choy, S. (2001). Students whose parents did not go to college: Postsecondary access, persistence, and attainment (NCES Report No. 2001-126). Retrieved from U.S. Department of Education, National Center for Education Statistics website: http://nces.ed.gov/ pubs2001/2001126.pdf

Chung, Y. B. (2003). Career counseling with lesbian, gay, bisexual, and transgendered persons: The next decade. The Career Development Quarterly, 52, 78-86.

Cook, E. P., Heppner, M. J., \& O'Brien, K. M. A (2002). Career development of women of color and White women: Assumptions, conceptualization, and interventions from an ecological perspective. The Career Development Quarterly, 50, 291-305.

Cuyjet, M. J. (1997). African American men on college campuses: Their needs and their perceptions. New Directions for Student Services, 80, 5-16.

De León, B. (1996). Career development of Hispanic adolescent girls. In B. J. R. Leadbeater \& N. Way (Eds.), Urban girls: Resisting stereotypes, creating identities (pp. 380-398). New York: New York University Press.

Falconer, J. W., \& Hays, K. A. (2006). Influential factors regarding the career development of African American college students: A focus group approach. Journal of Career Development, 32, 219-233.

Fleming, J. (1984). Blacks in college: A comparative study of students' success in Black and in White institutions. San Francisco, CA: Jossey-Bass.

Garibaldi, A. M. (1992). Educating and motivating African American males to succeed. Journal of Negro Education, 61, 4-11.

Gloria, A. M., Kurpius, S. E. R., Hamilton, K. D., \& Willson, M. S. (1999). African American students' persistence at a predominantly White university: Influence of social support, university comfort, and self-beliefs. Journal of College Student Development, $40,257-268$.

Hertel, J. B. (2002). College student generational status: Similarities, differences, and factors in college adjustment. Psychological Record, 52, 3-18.

Hoffman, M. B., Richmond, J. R., Morrow, J. A., \& Salomone, K. (2002). Investigating "sense of belonging" in first-year college students. Journal of College Student Retention: Research, Theory and Practice, 4, 227-256.

Hughes, C., Stenhjem, P. H., \& Newkirk, R. (2007). Poverty, race and youth: Challenges and promising practices in education. International Journal on School Disaffection, 5, $22-28$. 
Hurd, H. (2000). Staying power: Colleges work to improve retention rates. Black Issues in Higher Education, 17, 42-46.

Ishitani, T. T., \& DesJardins, S. L. (2002, June). A longitudinal investigation of dropout from college in the United States. Paper presented at the meeting of the Association for Institutional Research, Toronto, Canada. Retrieved from ERIC database. (ED473067)

Kimbrough, V. D., \& Salomone, P. R. (1993). African Americans: Diverse people, diverse career needs. Journal of Career Development, 19, 265-279.

Lee, C. C., \& Armstrong, K. L. (1995). Indigenous models of mental health intervention: Lessons from traditional healers. In J. G. Ponterotto \& J. M. Casas (Eds.), Handbook of multicultural counseling (pp. 441-456). Thousand Oaks, CA: Sage.

Lent, R. W., \& Brown, S. D. (1996). Social cognitive approach to career development: An overview. The Career Development Quarterly, 44, 310-321.

Locks, A. M., Bowman, N. A., Hurtado, S., \& Oseguera, L. (2006, April). Extending notions of campus climate and diversity to the transition to college: Experiences with diverse peers and college sense of belonging. Paper presented at the meeting of the American Educational Research Association, San Francisco, CA.

Murry, E., \& Mosidi, R. (1993). Career development counseling for African Americans: An appraisal of the obstacles and intervention strategies. Journal of Negro Education, 62, 441-447.

Noguera, P. A. (2005). The trouble with Black boys: The role and influence of environmental and cultural factors on the academic performance of African American males. In O. S. Fashola (Ed.), Educating African American males: Voices from the field (pp. 51-78). Thousand Oaks, CA: Corwin Press.

Parham, T. A., \& Austin, L. A. (1994). Career development and African Americans: A contextual reappraisal using the nigrescence construct. Journal of Vocational Behavior, $44,139-154$.

Snyder, T. D., \& Hoffman, C. M. (2003). Digest of Education Statistics, 2002: Table 183. College enrollment rates of high school completers, by race/ethnicity: 1960 to 2001 [Data table]. Retrieved from U.S. Department of Education, National Center for Education Statistics website: http://nces.ed.gov/programs/digest/d02/dt183.asp

Stoops, N. (2004). Educational attainment in the United States: 2003 (Current Population Reports, P20-550). Washington, DC: U.S. Census Bureau.

Sue, D. W., \& Sue, D. (2003). Counseling the culturally diverse: Theory and practice (4th ed.). New York, NY: Wiley.

Thayer, P. B. (2000, May). Retention of students from first generation and low income backgrounds. Journal of Opportunity in Education, 2-9.

Tinto, V. (2003, November). Promoting student retention through classroom practices. Paper presented at international conference on Enhancing Student Retention: Using International Policy and Practice, sponsored by the European Access Network and the Institute for Access Studies, Staffordshire University, Amsterdam, Netherlands. Retrieved from http://www.staffs.ac.uk/access-studies/docs/ Amster-paperVT(1).pdf

Townsend, L. (1994). How universities successfully retain and graduate Black students. Journal of Blacks in Higher Education, 4, 85-89.

Trusty, J. (2004). Effects of students' middle-school and high school experiences on completion of the bachelor's degree [Monograph]. Retrieved from Center for School Counseling Outcome Research, University of Massachusetts, Amherst website: http://www.umass. edu/schoolcounseling/PDFs/ResearchBrief2.1.pdf

U.S. Department of Education, National Center for Education Statistics. (2007). The condition of education 2007 (NCES Report No. 2007-064). Retrieved from http://nces. ed.gov/pubs2007/2007064.pdf

Walsh, W. B., Bingham, R. P., Brown, M. T., \& Ward, C. M. (2001). Career counseling for African Americans. Mahwah, NJ: Erlbaum. 
Wasonga, T., Christman, D. E., \& Kilmer, L. (2003). Ethnicity, gender and age: Predicting resilience and academic achievement among urban high school students. American Secondary Education, 32, 62-74.

Whiston, S. C. (2003). Career counseling: 90 years old yet still healthy and vital. The Career Development Quarterly, 52, 35-42.

Wilson, M. (2000). Reversing the plight of African American male college students. Black Issues in Higher Education, 17, 175. 